\title{
A Retrospective Study of the Inpatient Investigations and Management Performed in Acute Bronchiolitis in a Community Hospital \\ R Anmolsingh ${ }^{1}$, T Nasqidashvili ${ }^{2}$, K Wallace ${ }^{2}$, U Ajuze ${ }^{3}$, A Ratteray ${ }^{4}$, A Osseyran-Foggo ${ }^{4}$, S Carey $^{4}$, E Outerbridge ${ }^{1}, \mathrm{C}$ Wilson ${ }^{4}$
}

\begin{abstract}
Objective: To review the management/investigations performed in acute bronchiolitis.

Method: A retrospective study was conducted on 75 infants with clinical symptoms of bronchiolitis. Demographic and clinical data on the infants and compliance with the American Academy of Pediatrics (AAP) British Thoracic Society/ Scottish Intercollegiate (BTS/SIGN) Guidelines were examined.
\end{abstract}

Results: Fifty-seven per cent of infants were positive for respiratory syncytial virus (RSV). Seventy two per cent of infants had symptoms of rhinorrhoea. Thirty-two per cent of infants had crackles on chest auscultation. Forty-four per cent of infants had an abnormal chest X-ray. Twelve per cent of infants presented with an oxygen saturation $\mathrm{SAO}_{2}$ of less than 92 per cent. Seventy-seven per cent of infants received a bronchodilator. Thirty-five per cent of infants were given steroids. Thirty-two per cent of infants were treated with antibiotics.

Conclusion: The findings of this study can be used as a process improvement, which could result in reduced costs of care. In addition, the data generated by the study can be used to identify the start of the RSV season in order to best initiate RSV prophylaxis for risk groups of patients.

Keywords: American Academy of Pediatrics Guidelines, bronchiolitis, Scottish Intercollegiate Guidelines Network

From: ${ }^{1}$ Department of Paediatrics, ${ }^{2}$ Department of Medicine, ${ }^{3}$ Department of Surgery and ${ }^{4}$ Departments of Pathology and Microbiology, King Edward VII Memorial Hospital, Bermuda.

Correspondence: Dr Clyde Wilson, Departments of Pathology and Microbiology, King Edward VII Memorial Hospital, PO Box HM 1023, Hamilton HM DX Bermuda. Fax: 441-239-2193, E-mail: clyde.wilson@bhb.bm 


\section{INTRODUCTION}

Bronchiolitis is a common lower respiratory tract infection affecting around 10 per cent of infants in their first year of life. Respiratory syncytial virus is the pathogen responsible for around 75 per cent of cases of bronchiolitis (1). However, other viruses such as influenza, parainfluenza and adenovirus can produce the same clinical presentation (2). The diagnosis of bronchoilitis is based on clinical features such as: fever, cough, wheezing, feeding difficulties, rapid distressed breathing tachycardia and apnoea. The AAP and BTS/SIGN guidelines, were developed to help reduce the use of unnecessary investigations and therapies in the management

of infants with bronchiolitis. This study was undertaken to review the investigations and management of infants admitted with bronchiolitis in a community hospital over a three-year period.

\section{SUBJECTS AND METHODS}

A total of 75 sets of case notes were reviewed retrospectively of infants less than two-years of age with a diagnosis of bronchiolitis at the King Edward VII Memorial Hospital, a 250-bed community hospital, over a three-year period starting in December 2006 through to October 2009. The diagnosis of brochiolitis was based on the clinical features of the disease such as: fever, cough, wheezing, rhinorrhoea, dyspnoea and crackles/crepitations. Clinical investigations and management were reviewed. 


\section{RESULTS}

During the period of study, 75 infants (49 males and 26 females) were diagnosed with bronchiolitis. Forty-three infants, (57\%) were RSV positive. The number of RSV positive cases was higher in September, 2007 and January, 2009. However, there were notable cases in other months during the study period (Figure).

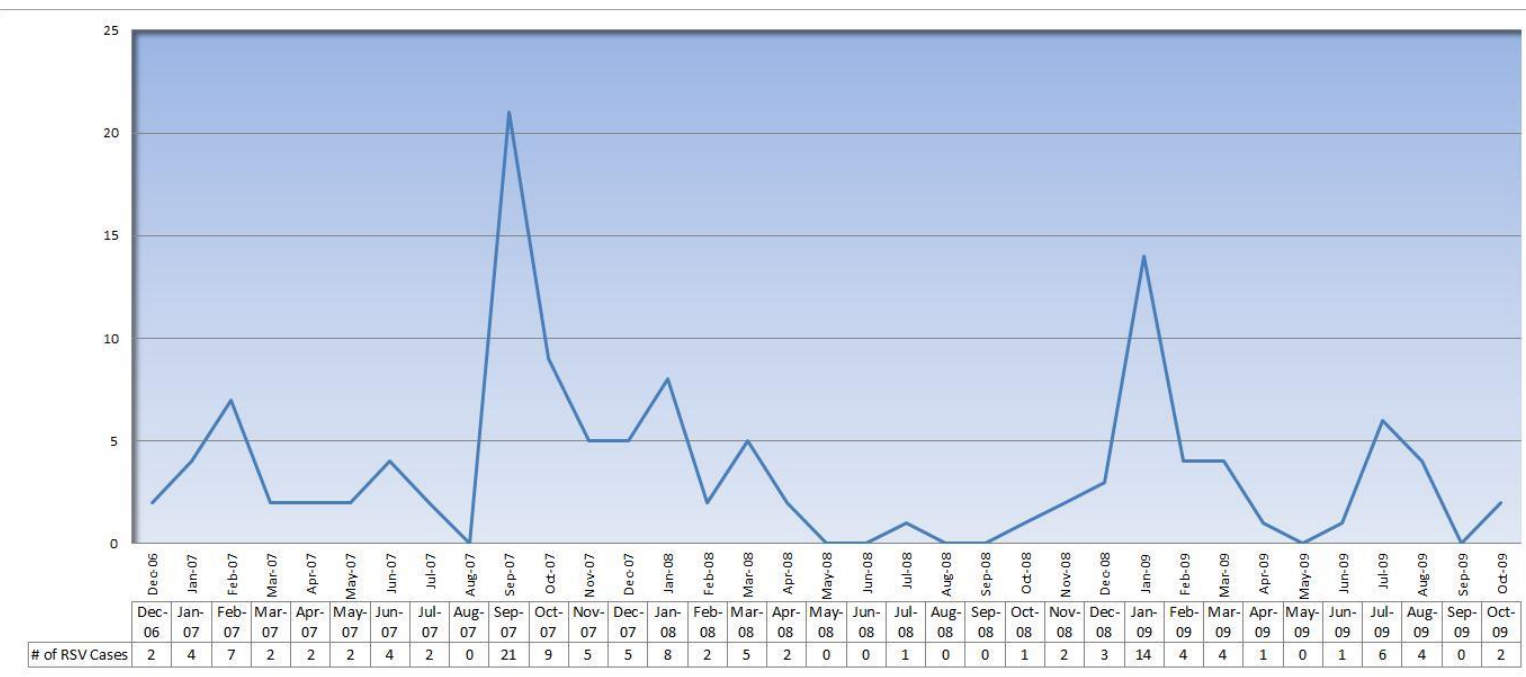

Figure: The number of RSV positive cases from December 2006 to October 2009.

Sixty-six infants, (88\%) presented with a cough. Forty-four infants, (59\%) were febrile. Fortyseven infants, (63\%) had symptoms of wheezing. Fifty-four infants, (72\%) presented with rhinorrhoea. Twenty-four infants, (32\%) had crackles on chest auscultation. Sixty-one patients (81\%) had a chest X-ray performed, of which 41 were abnormal (55\%). The number of infants with a $\mathrm{SAO}_{2}$ of less than 92 per cent was nine (12\%). Fifty-nine infants, (79\%) received fluids for severe dehydration. Twenty-four infants, (32\%) were given antibiotics. Fifty-eight infants, (77\%) had a bronchodilator and received atrovent or salbutamol. Twenty-six infants, 
(35\%) received steroids. The average age was 11 months (range 1-36 months) and the mean duration of hospital stay 2 days (range 1-8 days).

\section{DISCUSSION}

According to the BTS/SIGN guidelines, a diagnosis of acute bronchiolitis should be considered in an infant with nasal discharge and wheezy cough, in the presence of fine inspiratory crackles and/or high pitched expiratory wheeze. In addition to the common features of nasal discharge, rales and wheezy cough in bronchiolitis, the AAP guidelines include symptoms of increased respiratory effort manifested as grunting, nasal flaring and subcostal and or intercostal recessions. Healthcare professionals assessing infants that present with possible acute bronchiolitis may carry out investigations when diagnostic uncertainty exists. It is important to note that there are a number of other conditions that can also mimic acute bronchiolitis. Pulmonary causes of bronchiolitis-like symptoms include asthma, pneumonia, congenital lung disease, cystic fibrosis and inhaled foreign body. The majority of infants in our study presented with wheezing, rhinorrhoea and cough all of which are in agreement with the AAP and BTS/SIGN guidelines which state that these three features are common in acute bronchiolitis.

It is well documented in the literature that RSV is the most common cause of acute bronchiolitis. In our study, 43 infants, 57 per cent were RSV positive which is similar to the results obtained from studies carried out in North Carolina, 44.3 per cent (3), Colombia, 56 per cent (4) and Singapore, 50 per cent (5). Our RSV season seems to peak in September 2007, January 2008 and January 2009. The average monthly temperature and humidity in Bermuda for January and September is 68 degrees Fahrenheit, 82 degrees Fahrenheit, 73 per cent 
and 72 per cent, respectively. Furthermore, predictable seasonal epidemics in many parts of the world are the most notable features of RSV bronchiolitis (6). The median time of onset of the epidemic in the United States of America (USA) has been reported to be in late December, with a peak in early February (7). Interestingly, there have also been reports of distinct variations within the USA, with earlier seasons in the South and late ones in the Midwest. In the United Kingdom (UK) and Northern Europe the season is in December and January whereas in South America and South Africa, epidemics occur during the cool dry season (1).

Oxygen is the only agent that consistently reduces hypoxaemia in acute bronchiolitis. Furthermore, the standard criteria regarding oxygen therapy is that oxygen will be given if arterial oxygen saturation $\mathrm{SAO}_{2}$ is less than 92 per cent (8). In our study, only nine infants required oxygen therapy. The BTS/SIGN guidelines recommend that pulse oximetry should be performed in every child who presents to a healthcare facility with acute bronchiolitis and infants with oxygen saturation less than 92 per cent require in patient management. The AAP guidelines indicate that supplemental oxygen should be administered when the $\mathrm{SAO}_{2}$ falls persistently below $90 \%$ in previously healthy infants. The BTS/SIGN guidelines state that chest X-rays should not be performed on infants with typical acute bronchiolitis but should be considered in those infants where there is diagnostic uncertainty or an atypical disease course. In our study, 61 infants had a chest X-ray performed, of which 27 were abnormal. In a systemic review of the use of chest X-ray in acute bronchiolitis, it was concluded that, in mild disease, chest X-ray provides no information that is likely to affect treatment (9). Several infants in our study were given bronchodilators, antibiotics and steroids. The AAP and BTS/SIGN guidelines do not recommend their routine use in acute bronchiolitis. 
Several studies have shown that there is a high degree of variation in the management of infants with bronchiolitis internationally $(10,11)$. The AAP and BTS/SIGN guidelines were developed to provide an evidence based approach to the diagnosis and management of acute bronchiolitis to improve care in both outpatient and hospital settings. Furthermore, there is also much controversy, confusion and lack of evidence regarding the best treatment options for this condition (12). Currently, supportive care, including giving appropriate fluid replacement and oxygen are recommended in the management of acute bronchiolitis. Although the number of patents in the study was small, important and useful information was obtained which will be of use as a process improvement in the investigations and management of infants with acute bronchiolitis. 


\section{REFERENCES}

1. Simones EA, Carbonell-Estrany X. Impact of severe disease caused by respiratory syncytial virus in children living in developed countries. Pediatr Infect Dis J 2003; 22 (Suppl 2): S13-18.

2. Milner AD, Murray M. Acute bronchiolitis in infancy: treatment and prognosis. Thorax 1989; 44: $1-5$.

3. Henderson FW, Clyde WA, Collier AM, Denny FW, Senior RJ, Sheaffer CI et al. The etiological and epidemiologic spectrum of bronchiolitis in pediatric practice. J Pediatr 1979; 95: 83-90.

4. Berman S, Duenas A, Bedoya A, Constain V, Leon S, Borrero I et al. Acute lower respiratory tract illness in Cali, Colombia: A two year ambulatory study. Pediatrics 1983; 71: $210-18$.

5. Wong HB, Aiyathurai JE, Tay JS, Teo J, Quak SH, Sothy SP et al. Acute bronchiolitis in infancy. J Singapore Paed Soc 1983; 25: 89-95.

6. Williams JV, Harris PA, Tollefson SJ, Halburnt-Rush LL, Pingsterhaus JM, Edwards KM et al. Human metapneumovirus and lower respiratory tract disease in otherwise healthy infants and children. N Engl J Med 2004; 350: 443-50.

7. Mullins JA, Lamonte AC, Bresee JS, Anderson LJ. Substantial variability in community respiratory syncytial virus season timing. Pediatr Infect Dis J 2003; 22: 857-62.

8. Rakshi K, Couriel JM. Management of acute bronchiolitis. Archives of Disease in childhood 1994; 71: 463-69. 
9. Viswanathan M, King VJ, Bordley C, Honeycutt AA, Wittenborn J, Jackman AM et al, Management of bronchiolitis in infants and children. Rockville (MD):U.S. Department of Health and Human Services, Agency for Healthcare Research and Quality; 2003. Evidence Report/Technology Assessment Number 69. (cited 22 August 2006). Available from url: http;//www.ahrg.gov/clinic/tp/bronctp.htm.

10. Mansbach JM, Emond JA, Camargo jr CA. Bronchiolitis in US emergency departments 1992 to 2000: epidemiology and practice variation. Pediar Emerg Care 2005; 21: 242-47.

11. Vogel AM, Lennon DR, Harding JE, Pinnock RE, Graham DA, Grimwood K et al. Variations in bronchiolitis management between five New Zealand hospitals: can we do better? J Paediatr Child Health 2003; 39: 40-45.

12. Scarfone RJ. Controversies in the treatment of bronchiolitis. Curr Opin Pediatr 2005; 17: $62-66$. 